\title{
Nitrergic modulation of vasopressin, oxytocin and atrial natriuretic peptide secretion in response to sodium intake and hypertonic blood volume expansion
}

R.R. Ventura1, D.A. Gomes' ${ }^{1}$ W.L. Reis ${ }^{1}$, L.L.K. Elias ${ }^{1}$,

M. Castro ${ }^{1}$, M.M. Valença ${ }^{3}$, E.C. Carnio ${ }^{2}$, V. Rettori ${ }^{4}$, S.M. McCann ${ }^{5}$ and J. Antunes-Rodrigues ${ }^{1}$

\section{Correspondence}

J. Antunes-Rodrigues

Departamento de Fisiologia

FMRP, USP

Av. Bandeirantes, 3900

14049-900 Ribeirão Preto, SP

Brasil

E-mail: antunes@fmrp.usp.br

Presented at the IV International Symposium on Vasoactive Peptides, Belo Horizonte, MG, Brazil,

October 19-21, 2001.

Research supported by CNPq, FAPESP, CAPES and PRONEX

Received February 15, 2002 Accepted March 12, 2002

\author{
${ }^{1}$ Departamento de Fisiologia, Faculdade de Medicina de Ribeirão Preto, \\ Universidade de São Paulo, Ribeirão Preto, SP, Brasil \\ ${ }^{2}$ Escola de Enfermagem de Ribeirão Preto, U niversidade de São Paulo, \\ Ribeirão Preto, SP, Brasil \\ ${ }^{3}$ Departamento de Neuropsiquiatria, Universidade Federal de Pernambuco, \\ Recife, PE, Brasil \\ ${ }^{4}$ Centro de Estudios Farmacologicos y Botanicos, CO NICET, Buenos Aires, Argentina \\ ${ }^{5}$ Pennington Biomedical Research Center, University of Louisiana, \\ Baton Rouge, LA, USA
}

\section{Abstract}

The central nervous system plays an important role in the control of renal sodium excretion. We present here a brief review of physiologic regulation of hydromineral balance and discuss recent results from our laboratory that focus on the participation of nitrergic, vasopressinergic, and oxytocinergic systems in the regulation of water and sodium excretion under different salt intake and hypertonic blood volume expansion (BVE) conditions. High sodium intake induced a significant increase in nitric oxide synthase (NOS) activity in the medial basal hypothalamus and neural lobe, while a low sodium diet decreased NOS activity in the neural lobe, suggesting that central NOS is involved in the control of sodium balance. An increase in plasma concentrations in vasopressin (AVP), oxytocin (OT), atrial natriuretic peptide (ANP), and nitrate after hypertonic BVE was also demonstrated. The central inhibition of NOS by L-NAME caused a decrease in plasma AVP and no change in plasma OT or ANP levels after BVE. These data indicate that the increase in AVP release after hypertonic BVE depends on nitric oxide production. In contrast, the pattern of OT secretion was similar to that of ANP secretion, supporting the view that $\mathrm{OT}$ is a neuromodulator of ANP secretion during hypertonic BVE. Thus, neurohypophyseal hormones and ANP are secreted under hypertonic BVE in order to correct the changes induced in blood volume and osmolality, and the secretion of AVP in this particular situation depends on NOS activity.
Key words

- Vasopressin

- Oxytocin

- ANP

- Nitric oxide

- Blood volume expansion

- Sodium diet 


\section{Central nervous system and hydromineral balance}

Precise regulation of body fluid osmolality is essential. Osmolality is controlled by a finely tuned, intricate homeostatic mechanism that operates by adjusting both the rate of water intake and excretion. The central nervous system (CNS) plays an important role in the control of renal sodium excretion (1-7). Considerable evidence indicates that the median preoptic area (MnPO), anterior lateral hypothalamus, subfornical organ (SFO), anterior portion of the third ventricle (AV3V), supraoptic nucleus (SON), paraventricular nucleus (PVN), organum vasculosum laminae terminalis (OVLT), habenula, stria medullaris, and medial septal area are organized in a neural circuit involved in the regulation of water and sodium intake and excretion (1-3). Natriuresis accompanied by kaliuresis is induced by cholinergic or adrenergic stimulation of the medial septal area, $\mathrm{MnPO}$, anterior lateral hypothalamus, SFO, and AV3V (1,4). Stimulation of AV3V with carbachol, a cholinergic drug, angiotensin II or hypertonic saline enhances natriuresis, which is blocked by the destruction of this brain area (1,4-7).

\section{Neurohypophyseal hormones and the control of sodium and water excretion}

Although the neuroendocrine control of sodium and water balance is not completely understood, alterations in volume and osmolality are responsible, at least in part, for changes in plasma vasopressin (AVP) concentration. Verney (8) originally demonstrated that AVP release into the blood is stimulated by the activation of osmoreceptors, which detect small increases in osmolality of extracellular fluid. These osmoreceptors are located in the $\mathrm{AV} 3 \mathrm{~V}$, which is made of a thin membrane, the lamina terminalis, comprising the MnPO, SFO and OVLT.
These organs lie outside the blood-brain barrier and therefore are in contact with plasma ions and hormones such as atrial natriuretic peptide (ANP) and angiotensin II $(9,10)$. Vasopressin is rapidly released in response to as little as $1 \%$ change in plasma osmolality (11). Small changes in plasma osmolality in the physiological range can rapidly stimulate AVP transcription in the SON and PVN, suggesting that stored AVP released into the blood circulation is replaced rapidly by increased synthesis, processing, and transport of AVP (12). The threshold for the activation of osmoreceptor neurons to stimulate AVP release is approximately $275 \mathrm{mOsm} / \mathrm{kg}$ (13). In addition, lesions of the AV3V cause adipsia and hypernatremia (2), impaired drinking responses and AVP secretion in response to hypertonic saline and angiotensin II (14), decrease of the number of Fos-like immunoreactive neurons in the MnPO, PVN and $\mathrm{SON}$ in response to $i v$ infusion of hypertonic saline (15), and interruption of neuronal inputs that trigger AVP secretion from the posterior pituitary as well as AVP release into the extracellular compartment of the SON (16).

Oxytocin (OT) is also involved in hydromineral homeostasis and vascular and cardiac relaxation (17-23). It has long been recognized that OT increases renal electrolyte excretion in various species, and that the natriuretic and kaliuretic effects are AVP independent. OT and AVP are secreted simultaneously in response to hyperosmolality and hypovolemia $(19,24,25)$ and when systemically administered ( $i v$ or $i p$ ) induce natriuresis $(26,27)$. OT is a more potent natriuretic hormone than AVP. These effects can be explained by a direct action of both peptides on specific receptors demonstrated to be present in kidney tubular cells (28). The different potencies of these hormones can be attributed to a relative affinity of OT for its own receptor or its lower affinity for V2 and V1 AVP receptors. On the other hand, studies have suggested a synergistic 
effect of AVP and OT actions on the inner medullary collecting duct where both peptides induce an increase in cAMP accumulation and natriuresis $(24,29)$. OT binds to the V2 AVP receptor because of its structural similarity to AVP. Vasopressin and OT induce cAMP accumulation from a common ATP pool in inner medullary collecting duct cells, and the separate AVP V2 and OT receptor systems may be coupled to a common adenylate cyclase system (30). In addition to their peripheral effects, these peptides may also have other effects that could complement their physiological actions. Indeed, AVP when injected into the CNS increases water intake, while the central administration of OT decreases salt intake (31).

\section{Natriuretic peptides and hydromineral balance}

De Bold et al. (32) demonstrated the diuretic effect of atrial extracts and later determined the structure of ANP (33). The myorelaxing action of the atrial extracts on vascular muscle was demonstrated independently by different groups (34-36). These findings permitted the identification and characterization of hormones of the natriuretic peptide family, which are involved in the control of body fluid homeostasis $(36,37)$. Atrial natriuretic peptide from the atria circulates to the kidneys and evokes diuresis and natriuresis.

Since ANP is the major natriuretic hormone, we determined the effect of central administration of hypertonic saline on plasma ANP levels. Microinjection of hypertonic saline into the AV3V causes an increase in plasma ANP levels (38). The effects of ANP on electrical activity and cellular cGMP levels in neurons of the SON of rat hypothalamic slices demonstrate that the osmotic stimulus induces ANP/BNP secretion in the hypothalamus which then inhibits AVP neurons (39). Interestingly, applications of ANP over the SON did not affect depolarizing responses to local hypertonicity, but reversibly abolished the synaptic excitation of magnocellular neurons after hypertonic stimulation of the OVLT (40). ANP and its receptors are present in the magnocellular neurosecretory cells, which release AVP and OT. In addition, these cells receive afferents from osmoreceptor neurons located in the OVLT which appear to be glutamatergic. Richard and Bourque (40) obtained results indicating that centrally released ANP may inhibit osmotically evoked neurohypophyseal hormone release by presynaptic inhibition of glutamate release from these osmoreceptor efferents derived from the OVLT.

Both median eminence lesions and removal of the neural lobe of the pituitary, conditions that partially block or eliminate neurohypophyseal hormone release, decrease basal and blood volume expansion (BVE)induced ANP release $(38,41)$. Several lines of evidence indicate a possible physiologic function of OT in the mediation of ANP release since $i p$ or $i v$ injection of OT causes a dose-dependent increase in plasma ANP, urinary osmolality, natriuresis, kaliuresis, and a delayed antidiuretic effect (19). Isotonic BVE releases OT and ANP, but not AVP. Therefore, OT would act directly on the right atrium to stimulate ANP release. Indeed, we found a dose-related release of ANP from in vitro incubated right atrium in the presence of OT (42). An OT antagonist blocked both the basal and OT-induced ANP release. In addition, the presence of OT in the right atrium homogenates was demonstrated by RIA (42) and more recently, OT and OT receptor synthesis have been demonstrated in the rat heart $(20,22)$. In addition, using polymerase chain reaction (PCR) amplification of cDNA obtained from mRNA of both rat atria and ventricles, the presence of specific transcripts was also demonstrated. The OT and OT receptor transcripts were also shown by in situ hybridization in atrial and ventricular tissues using RT-PCR $(22,43)$. Consequently, OT released from the neural lobe may reach the heart by the 
circulation to induce ANP release, but the intracardiac OT might also play a paracrine role in stimulating ANP release.

In addition to being affected by neurohypophyseal hormones, ANP released from the heart may reach the brain centers in sufficient concentrations to regulate its own secretion through a putative negative feedback mechanism. It has been reported that ANP and central natriuretic peptide injected into the AV3V region of BVE rats decreased plasma ANP concentration with no change in mean arterial pressure or heart rate. In contrast, in rats with normal blood volume, ANP injection into the AV3V did not affect circulating ANP (44). Moreover, icv ANP administration decreases natriuresis and also blocks cholinergic-induced natriuresis (45). The mechanism of these effects remains to be determined. Since ANP poorly penetrates the brain, it is unlikely that systemic levels of the peptide would sufficiently increase brain ANP to produce a feedback effect; however, a local increase of ANP from ANPergic neurons induced by volume expansion increases baroreceptor input to the hypothalamus and might inhibit ANP neuronal activity.

\section{Participation of the nitrergic system in hydromineral metabolism}

The discovery of nitric oxide (NO) as a neurotransmitter has radically altered the concept of synaptic transmission. NO was first recognized as a neuronal messenger molecule by Garthwaite et al. (46), who showed that glutamate, acting on the N-methyl-Daspartate receptor in cultures of cerebellar granule cells, releases a factor with properties resembling those of NO. It is now clear that NO has a physiological role in the regulation of water balance (47). NO synthase (NOS), an enzyme involved in the synthesis of NO and constitutively expressed in neurons and endothelial cells, utilizes the semiessential amino acid L-arginine, reducing equivalents from NADPH and molecular $\mathrm{O}_{2}$ to catalyze the formation of $\mathrm{NO}$ and its coproduct citrulline via a $\mathrm{Ca}^{2+}$-calmodulin-dependent mechanism. The enzyme protein and its mRNA have been identified in several structures within the neural circuitry that regulates body fluid homeostasis, including the hypothalamus-neurohypophyseal system, SFO, MnPO, and OVLT (48). These forebrain structures form a neural network that participates in the regulation of drinking behavior and secretion of AVP, OT and ANP in response to osmotic stimulation $(1,9,49)$.

The presence of nNOS in the PVN and SON vasopressinergic and oxytocinergic neurons and its increase in these neurons by osmotic stimulation or dehydration suggests a role of $\mathrm{NO}$ in AVP and OT regulation (50-52). It has been demonstrated that during dehydration the central inhibition of NOS preferentially augments OT release $(47,53)$. Interestingly, the increase in NO production in the PVN and SON of hypertensive rats was ineffective in inhibiting AVP secretion (54). Moreover, infusion of L-arginine, the substrate of NOS, or sodium nitroprusside, a spontaneous releaser of NO, into the $\mathrm{AV} 3 \mathrm{~V}$ produced a dose-related increase in plasma AVP levels (55). There still is some controversy about the role of $\mathrm{NO}$ in AVP and OT release, with some studies showing an inhibitory effect on AVP release in normovolemic rats (56-58), while others have indicated an excitatory effect on AVP release $(59,60)$. Therefore, the role of NO in the hormonal changes induced by osmotic and blood volume changes remains unclear. We have investigated the interaction between nitrergic and vasopressinergic systems in response to high and low sodium diets and to hypertonic BVE $(0.3 \mathrm{M} \mathrm{NaCl})$.

\section{Effect of high and low sodium diets on NOS activity in the neural lobe and medial basal hypothalamus}

To evaluate the effect of different so- 
dium content in the diet on NOS activity in the CNS regions, rats were treated with a high sodium diet $(1.8 \% \mathrm{NaCl})$ or a low sodium diet for 7 days before the experiments. The high sodium diet induced a significant increase in NOS activity in the medial basal hypothalamus as well as in the neural lobe. In contrast, the low sodium diet significantly decreased NOS activity in the neural lobe and did not induce changes in the medial basal hypothalamus (Figure 1). These data indicate that high sodium ingestion, and consequent changes in plasma osmolality and natremia, blood volume and pressure, increased NOS activity. Since opposite effects were observed with high and low sodium diets, it is suggested that central NOS has a role in the regulatory mechanisms involved in sodium balance.

\section{Blood volume expansion and nitrergic system}

Recent results from our laboratory have demonstrated that hypertonic saline BVE causes an increase in plasma nitrate after 5 min of expansion, followed by a return to basal levels 15 min later (Figure 2). These results indicate that an increase in blood volume or plasma osmolality, or both, could stimulate the production and release of NO. However, there are no significant changes in plasma nitrate following isotonic saline BVE (Figure 2), suggesting that the plasma nitrate increase is not due to changes in blood volume, but rather to osmotic load. The increase in plasma nitrate after BVE could be involved in the regulation of other hemodynamic parameters, such as mean arterial blood pressure and heart rate. Indeed, a short lived ( $2 \mathrm{~min}$ ) decrease in blood pressure was evident after hypertonic BVE, with a concomitant bradycardia that lasted about $10 \mathrm{~min}$ (Giusti-Paiva A, unpublished data).

The increase in nitrate content after hypertonic BVE was also observed in brain regions involved in the neuroendocrine con- trol of hydromineral homeostasis including the medial basal hypothalamus, neural lobe, and anterior lobe of the hypophysis. No changes were observed in the median eminence (Figure 3). In addition, hypertonic BVE also increased the plasma levels of
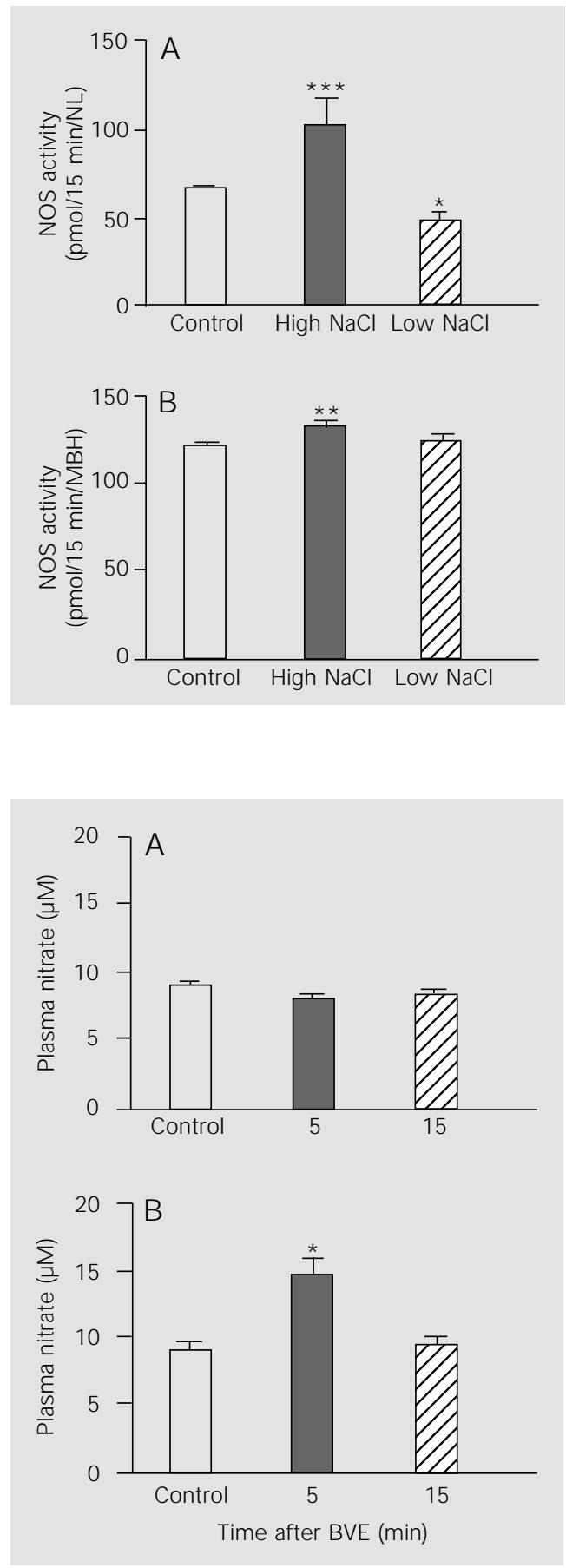

Figure 1. Effect of a chronic (7 days) high or low $\mathrm{NaCl}$ diet on nitric oxide synthase (NOS) activity in the neural lobe (NL) (A) and medial basal hypothalamus (MBH) (B) of adult male rats. Data are reported as means \pm SEM for 7-10 rats. $* P<0.05$, $* * P<0.01$ and $* * * P<0.001$ compared to control rats under regular $\mathrm{NaCl}$ diet (Student t-test).

Figure 2. Effect of isotonic $(0.15$ $\mathrm{M} \mathrm{NaCl}$ ) (A) or hypertonic (0.3 M $\mathrm{NaCl}$ (B) blood volume expansion (BVE; intrajugular injection of $2 \mathrm{ml} / 100 \mathrm{~g}$ body weight, over $1 \mathrm{~min}$ ) on plasma nitrate concentration before (control group), 5 and 15 min after BVE. Data are reported as means \pm SEM for 7-10 rats. $* \mathrm{P}<0.001$ compared to control (Student ttest). 
AVP, OT, and ANP (Figure 4). We also studied in rats the effect of central inhibition of NOS by $i c v$ injection of L-NAME on the increase in plasma ANP, OT and AVP induced by hypertonic BVE. In hydrated ani-
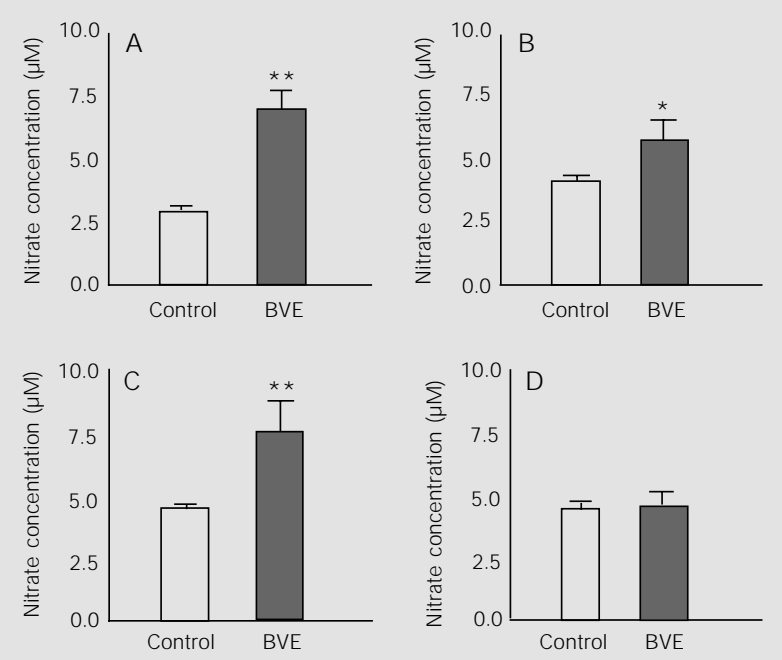

Figure 3. Effect of hypertonic $(0.3 \mathrm{M} \mathrm{NaCl})$ blood volume expansion (BVE) on nitrate content of medial basal hypothalamus (A), neural lobe (B), adenohypophysis (C) and median eminence (D). Data are reported as means \pm SEM for 7-10 rats, before (control) and 5 min after BVE. $* \mathrm{P}<0.01$ and $* * \mathrm{P}<0.001$ compared to control (Student t-test).
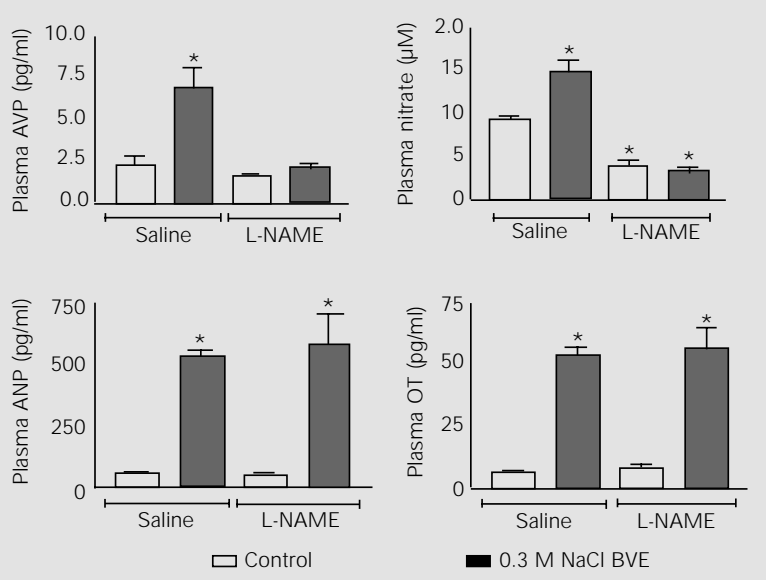

Figure 4. Effect of hypertonic $(0.3 \mathrm{M} \mathrm{NaCl})$ blood volume expansion (BVE) in rats pretreated or not with a NOS inhibitor (L-NAME, $10 \mathrm{mg} /$ $100 \mathrm{~g}$ body weight, $30 \mathrm{~min}$ before) on plasma levels of nitrate, vasopressin (AVP), oxytocin (OT), and atrial natriuretic peptide (ANP). Data are reported as means \pm SEM for 7-10 rats, before (control) and 5 min after BVE. *P<0.001 compared to saline control group (oneway ANOVA followed by Newman-Keuls test). mals, the $i c v$ injection of L-NAME did not cause significant changes in basal plasma ANP, OT or AVP concentrations. However, this pretreatment blocked the hypertonic BVE-induced increase in plasma AVP and nitrate levels, with no changes in plasma ANP or OT levels (Figure 4).

\section{Summary}

This brief review presents studies from our laboratory that focus on the participation of nitrergic, vasopressinergic, and oxytocinergic neuronal systems in the regulation of hydromineral balance under basal or hypertonic BVE-stimulated conditions. The concept of NO as a neurotransmitter has evolved. Several studies have demonstrated the participation of NO in neurosecretory activities; however, there still is controversy about the nitrergic modulation of AVP, ANP and OT secretion in response to hypertonic BVE. The increase in plasma concentrations of AVP, OT, and ANP and plasma nitrate elevation after hypertonic BVE suggest that the nitrergic system is activated in response

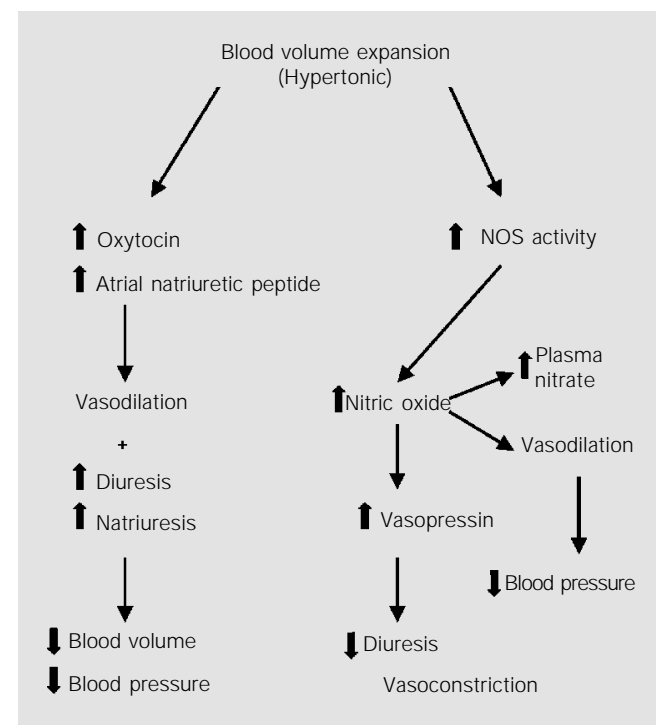

Figure 5. Schematic representation of hormonal changes, nitric oxide production and hemodynamic modifications after hypertonic blood volume expansion. NOS = nitric oxide synthase. 
to hypertonic BVE. However, the central inhibition of NOS with L-NAME showed an evident dissociation in the secretory pattern of neurohypophyseal hormones, with a decrease in AVP and no changes in OT or ANP plasma levels. These data indicate that the increase in AVP release after hypertonic $\mathrm{BVE}$ is dependent on $\mathrm{NO}$ production. On the other hand, the pattern of OT secretion was similar to that of ANP, suggesting that whenever blood concentration of OT changes, a parallel modification in ANP levels occurs. Taken together with published data from our laboratory, these data support the hypothesis that OT acts as a neuromodulator of ANP secretion. In Figure 5 we present a diagram summarizing the interaction of NO neurons and the regulation of AVP, ANP and OT secretion during hypertonic BVE.

\section{Acknowledgments}

We thank Marina Holanda, Maria Valci Aparecida de Souza Adriana Rossi and Lucimara Bueno for technical assistance.

\section{References}

1. Covian MR, Antunes-Rodrigues J, Gentil CG, Saad WA, Camargo LAA \& Silva-Netto CR (1975). Central of salt balance. In: Mogenson GJ \& Calaresu FR (Editors), Neural Integration of Physiological Mechanisms and Behavior. University of Toronto, Toronto, Ontario, Canada.

2. Franci CR, Silva-Netto CR, Saad WA, Camargo LA \& Antunes-Rodrigues J (1980). Interaction between the lateral hypothalamic area (LHA) and the medial septal area (MSA) in the control of sodium and potassium excretion in rats. Physiology and Behavior, 25: 801-806.

3. Franci $C R$, Antunes-Rodrigues J, SilvaNetto CR, Camargo LAA \& Saad WA (1983). Identification of pathways involved in the natriuretic, kaliuretic and diuretic responses induced by cholinergic stimulation of the medial septal area (MSA). Physiology and Behavior, 30: 65-71.

4. Dom A, Antunes-Rodrigues J \& McCann SM (1970). Natriuresis in the rat following intraventricular carbachol. American J ournal of Physiology, 219: 1292-1298.

5. Ramsay DJ , Thrasher TN \& Keil LC (1983). The organum vasculosum laminae terminalis: a critical area for osmoreception. Progress in Brain Research, 60: 91-98.

6. Bealer SL, Phillips MI, J ohnson AK \& Schmid PG (1979). Anteroventral third ventricle lesions reduce antidiuretic responses to angiotensin II. American J ournal of Physiology, 236: E610-E615.

7. McKinley MJ, Denton DA, Coghlan JP, Harvey RB, McDougall J G, Rundgren M, Scoggins BA \& Weisinger RS (1987). Cerebral osmoregulation of renal sodium excretion - a response analogous to thirst and vasopressin release. Canadian J our- nal of Physiology and Pharmacology, 65: 1724-1729.

8. Vemey EB (1947). The antidiuretic hormone and the factors which determine its release. Proceedings of the Royal Society of London, 135: 25-105.

9. J ohnson AK \& Gross PM (1993). Sensory circumventricular organs and brain homeostatic pathways. FASEB J oumal, 7: 678-686.

10. McKinley MJ, Gerstberger R, Mathai ML, Oldfield BJ \& Schmid H (1999). The lamina terminalis and its role in fluid and electroIyte homeostasis. J oumal of Clinical Neuroscience, 6: 289-301.

11. Bisset GW, Chowdrey HS \& Feldebeeg W (1978). Release of vasopressin by enkephalin. British J ournal of Pharmacology, 62: 370-371.

12. Arima $\mathrm{H}$, Kondo $\mathrm{K}$, Kakiya S, Nagasaki $\mathrm{H}$, Yokoi $\mathrm{H}$, Yambe $\mathrm{Y}$, Murase T, Iwasaki $Y$ \& Oiso $Y$ (1999). Rapid and sensitive vasopressin heteronuclear RNA responses to changes in plasma osmolality. J ournal of Neuroendocrinology, 11: 337-341.

13. Bourque CW, Oliet SH \& Richard D (1994). Osmoreceptors, osmoreception, and osmoregulation. Frontiers in Neuroendocrinology, 15: 231-274.

14. Knepel W, Nutto D \& Mayer DK (1982). Effect of transection of SFO efferent projections on AVP release induced by A-II or isoprenaline in the rat. Brain Research, 248: 180-184.

15. Hochstenbach SL \& Ciriello J (1995). Plasma hypematremia induces c-fos activity in medullary catecholaminergic neurons. Brain Research, 674: 46-54.

16. Ludwig $M$, Callahan $M F$, Landgraf $R$, J ohnson AK \& Morris M (1996). Neural input modulates osmotically stimulated release of AVP into the supraoptic nucleus. American J ournal of Physiology, 270: E787-E792.

17. Conrad KP, Gellai M, North WG \& Valtin H (1986). Influence of oxytocin on renal hemodynamics and electrolyte and water excretion. American J oumal of Physiology, 251: F290-F296.

18. Huang W, Lee S-L \& Sjöquist M (1995). Natriuretic role of endogenous oxytocin in male rats infused with hypertonic $\mathrm{NaCl}$. American J ournal of Physiology, 268: R634-R640.

19. Haanwinckel MA, Elias LK, Favaretto ALV Gutkowska J, McCann SM \& AntunesRodrigues J (1995). Oxytocin mediates atrial natriuretic peptide release and natriuresis after volume expansion in the rat. Proceedings of the National Academy of Sciences, USA, 92: 7902-7906.

20. Gutkowska J, J ankowski M, Lambert C, Mukaddam-Daher S, Zingg HH \& McCann SM (1997). Oxytocin releases atrial natriuretic peptide by combining with oxytocin receptors in the heart. Proceedings of the National Academy of Sciences, USA, 94: 11704-11709.

21. Soares TJ, Coimbra TM, Martins AR, Pereira AG, Carnio EC, Branco LG, Albuquerque-Araújo WI, Nucci GD, Favaretto AL, Gutkowska J , McCann SM \& AntunesRodrigues J (1999). Atrial natriuretic peptide and oxytocin induce natriuresis by release of CGMP. Proceedings of the National Academy of Sciences, USA, 96: 278-283.

22. Jankowski $M$, Wang D, Hajjar $F$, Mukaddam-Daher S, McCann SM \& Gutkowska J (2000). Oxytocin and its re- 
ceptors are synthesized in the rat vasculature. Proceedings of the National Academy of Sciences, USA, 97: 6207-6211.

23. Gutkowska J, J ankowski M, MukaddamDaher S \& McCann SM (2000). Oxytocin is a cardiovascular hormone. Brazilian J ournal of Medical and Biological Research, 33: 625-633.

24. Balment RJ , Brimble MS \& Forsling ML (1980). Release of oxytocin induced by salt loading and its influence on renal excretion in the male rat. J ournal of Physiology, 308: 439-449.

25. Stricker EM \& Verbalis J G (1986). Interaction of osmotic and volume stimuli in the regulation of neurohypophysial secretion in rats. American J ournal of Physiology, 250: R267-R275.

26. Fraser AM (1942). Actions of oxytoxic hormone of pituitary gland on urine secretion. J ournal of Physiology, 101: 238-251.

27. Sawyer WH (1952). Posterior pituitary extraction and excretion of electrolytes by rat. American J oumal of Physiology, 169: 583-587.

28. Stoeckel ME, Freund-Mercier MS, Falacios J M, Richard P \& Porte A (1987). Autoradiographic localization of binding sites for oxytocin and vasopressin in the rat kidney. J ournal of Endocrinology, 113: 179-182.

29. Forsling $M L$, Brimble $M J \&$ Balment RJ (1982). The influence of vasopressin on oxytocin-induced changes in urine flow in the male rat. Acta Endocrinologica, 100: 216-220

30. Wargent ET, Burgess WJ, Laycock J F \& Balment RJ (1999). Separate receptors mediate oxytocin and vasopressin stimulation of CAMP in rat inner medullary collecting duct cells. Experimental Physiology, 84: 17-25.

31. Stricker EM \& Verbalis J G (1988). Hormones and behavior. Biological basis of thirst and sodium appetite. American Scientist, 76: 261-267.

32. De Bold AJ , Borenstein HB, Veress AT \& Sonnenberg H (1981). A rapid and potent natriuretic response to intravenous injection of atrial myocardial extract in rats. Life Sciences, 28: 89-94.

33. Flynn TG, De Bold ML \& De Bold AJ (1983). The amino acid sequence of an atrial peptide with potent diuretic and natriuretic properties. Biochemical and Biophysical Research Communications, 117: 859-865.

34. Deth RC, Wong K, Fukozawa S, Rocco R, Smart J L, Lynch CJ \& Awad R (1982). Inhibition of rat aorta contractile response by natriuresis-inducing extract of rat atrium. Federation Proceedings, 41: 983 (Abstract).

35. Currie MG, Geller DM, Cole BR, Boylan J G, Yusheng W, Holmberg SW \& Needleman P (1983). Bioactive cardiac substances: potent vasorelaxant activity in mammalian atria. Science, 221: 71-73.

36. Forssmann WG, Hock D, Flottspeich W, Henschen A, Kreye V, Christmann $M$, Reinecke M, Metz J , Carlquist M \& Mutt $V$ (1983). The right auricle of the heart is an endocrine organ: cardiodilatin as a peptide hormone candidate. Anatomical Embryology, 168: 307-313.

37. Kangawa K \& Matsuo H (1984). Purification and complete amino acid sequence of alpha-human atrial natriuretic polypeptide (alpha-hANP). Biochemical and Biophysical Research Communications, 118: 131-139.

38. Antunes-Rodrigues J, Ramalho MJ, Reis LC, Menani J V, Turin Q, Gutkowska J \& McCann SM (1991). Lesions of the hypothalamus and pituitary inhibit volume-expansion-induced release of atrial natriuretic peptide. Proceedings of the National Academy of Sciences, USA, 88: 29562960.

39. Akamatsu $\mathrm{N}$, Inenaga $\mathrm{K} \&$ Yamashita $\mathrm{H}$ (1993). Inhibitory effects of natriuretic peptides on vasopressin neurons mediated through CGMP and CGMP-dependent protein kinase in vitro. J ournal of Neuroendocrinology, 5: 517-522.

40. Richard D \& Bourque CW (1996). Atrial natriuretic peptide modulates synaptic transmission from osmoreceptor afferents to the supraoptic nucleus. J ournal of Neuroscience, 16: 7526-7532.

41. Morris M, McCann SM \& Orias R (1976). Evidence for hormonal participation in the natriuretic and kaliuretic responses to intraventricular hypertonic saline and norepinephrine. Proceedings of the Society for Experimental Biology and Medicine, 152: 95-98.

42. Favaretto AL, Ballejo GO, AlbuquerqueAraujo WI, Gutkowska J, AntunesRodrigues J \& McCann SM (1997). Oxytocin releases atrial natriuretic peptide from rat atria in vitro that exerts negative inotropic and chronotropic action. Peptides, 18: 1377-1381.

43. J ankowski M, Hajjar F, Kawas SA, Mukaddam-Daher S, Hoffman G, McCann SM \& Gutkowska J (1998). Rat heart: a site of oxytocin production and action. Proceedings of the National Academy of Sciences, USA, 95: 14558-14563.

44. Puyo AM, Vatta MS, Donoso AS, Bianciotti LG \& Fernandez BE (2000). Cen- tral natriuretic peptides regulation of peripheral atrial natriuretic factor release. Regulatory Peptides, 90: 93-99.

45. Elias LLK, Castro M, Baldissera S, McCann SM \& Antunes-Rodrigues J (2001). Cholinergic stimulation of the antero-ventral region of third ventricle (AV3V) on sodium excretion: participation of atrial natriuretic peptide (ANP) and vasopressin. 5th European Congress of Endocrinology, Turin, Italy, J une 9-13, 2001, 99 (Abstract).

46. Garthwaite J, Charles SL \& ChessWilliams R (1988). Endothelium-derived relaxing factor release on activation of NMDA receptors suggests role as intracellular messenger in the brain. Nature, 336: 385-388.

47. Summy-Long J Y, Bui V, Mantz S, Koehler E, Weisz J \& Kadekaro M (1993). Central inhibition of nitric oxide synthase preferentially augments release of oxytocin during dehydration. Neuroscience Letters, 152: 190-193.

48. Bredt DS, Glatt CE, Hwang PM, Fotuhi M, Dawson TM \& Snyder SH (1991). Nitric oxide synthase protein and mRNA are discretely localized in neuronal populations of the mammalian CNS together with NADPH diaphorase. Neuron, 7: 615-624.

49. Gutkowska J, Antunes-Rodrigues J \& McCann SM (1997). Atrial natriuretic peptide in brain and pituitary gland. Physiological Reviews, 77: 465-515.

50. Bredt DS, Hwang PM \& Snyder SH (1990). Localization of nitric oxide synthase indicating a neural role for nitric oxide. Nature, 347: 768-770.

51. Villar MJ, Ceccatelli S, Ronnqvist $M \&$ Hokfelt T (1994). Nitric oxide synthase increases in hypothalamic magnocellular neurons after salt loading in the rat. An immunohistochemical and in situ hybridization study. Brain Research, 644: 273281.

52. Hatakeyama S, Kawai $Y$, Ueyama $T \&$ Senba E (1996). Nitric oxide synthase-containing magnocellular neurons of the rat hypothalamus synthesize oxytocin and vasopressin and express Fos following stress stimuli. J oumal of Chemical Neuroanatomy, 11: 243-256.

53. Kadekaro $M$, Terrell ML, Pamela $\mathrm{H}$ \& Summy-Long J Y (1994). Central inhibition of nitric oxide synthase attenuates water intake but does not alter enhanced glucose utilization in the hypothalamo-neurohypophysial system of dehydrated rats. Neuroscience Letters, 173: 115-118.

54. Serino $R$, Ueta $Y$, Hanamiya $M$, Nomura $M$, Yamamoto $Y$, Yamaguchi K, Naka- 
shima Y \& Yamashita H (2001). Increased levels of hypothalamic neuronal nitric oxide synthase and vasopressin in saltloaded Dahl rat. Autonomic Neuroscience, 87: 225-235.

55. Yamaguchi $K$, Watanabe $K$ \& Yamaya $K$ (2000). Evaluation for roles of nitric oxide generated in the anteroventral third ventricular region in controlling vasopressin secretion and cardiovascular system of conscious rats. European J ournal of Endocrinology, 143: 523-533.

56. Bemadette LB \& Bemard K (1994). Evi- dence for an inhibitory effect of nitric oxide on neuropeptide secretion from isolated neural lobe of the rat pituitary gland. Neuroscience Letters, 165: 48-50.

57. Kadekaro M, Liu H, Terrell ML, Gestl S, Bui $V \&$ Summy-Long J Y (1997). Role of $\mathrm{NO}$ on vasopressin and oxytocin release and blood pressure responses during osmotic stimulation in rats. American J ournal of Physiology, 363: R1024-R1030.

58. Qing-Song L, You-Sheing J \& Gong J (1997). Nitric oxide inhibits neuronal activity in the supraoptic nucleus of the rat hypothalamic slices. Brain Research Bulletin, 43: 121-125.

59. Masahiro O, J ean TC, Gregory TF \& Leonard S (1993). Evidence that nitric oxide can act centrally to stimulate vasopressin release. Neuroendocrinology, 57: 955-959.

60. Luxiang C, Xia $S \&$ Eh S (1996). Nitric oxide stimulates both basal and reflex release of vasopressin in anesthetized rats. Neuroscience Letters, 221: 49-52. 